Saudi Journal of Oral and Dental Research

Abbreviated Key Title: Saudi J Oral Dent Res ISSN 2518-1300 (Print) |ISSN 2518-1297 (Online) Scholars Middle East Publishers, Dubai, United Arab Emirates Journal homepage: http://scholarsmepub.com/sjodr/

\title{
Screening of Dental Plaque for Presence of Streptococcus Mutans Bacteriophages
}

\author{
Dr. Nazish Munir Mohamedhussein ${ }^{1 *}$, Dr. J I Foley ${ }^{2}$ \\ ${ }^{1}$ Paediatric Dentist, Dr Dina Pediatric Dental Clinic, Dubai, U.A.E \\ ${ }^{2}$ Senior Clinical Lecturer/Honorary Consultant, Edinburgh Dental Institute, Edinburgh, United Kingdom
}

DOI: $10.36348 /$ sjodr.2020.v05i01.009

| Received: 08.11.2019 | Accepted: 15.11.2019 | Published: 22.01 .2020

*Corresponding author: Dr. Nazish Munir Mohamedhussein

Abstract

Background: The aetiology of dental caries is multifactorial and all contributing factors have been studied extensively. Streptococcus mutans ( $S$. mutans) has been implicated as a primary odontopathogen and is an important target in caries prevention and management. Bacteriophage therapy is an antibacterial therapy that has garnered interest in human and veterinary medicine due to its numerous advantages. Bacteriophages are more numerous than bacteria and are highly specific and may be used to target $S$. mutans without disturbing the remaining oral flora. Aim: The purpose of this study was to isolate $S$. mutans from dental plaque and to attempt to isolate $S$. mutans-specific bacteriophages from the same material. Methodology: Plaque samples were obtained from patients using sterile swabs with transport medium. Samples were serially diluted and plated on TYCSB selective media. Suspect colonies (based on morphological appearance) were subjected to biochemical tests (catalase test and Gram staining). The presumptive identity of isolated bacterial colonies as $S$. mutans was confirmed molecularly (PCR, followed by electrophoresis). A filtrate prepared from dental plaque samples was used in spot assays against the $S$. mutans isolates to screen for presence of bacteriophages having lytic activity against them. Results: Seven isolates of $S$. mutans were obtained and a single bacteriophage having lytic activity against one of these isolates was recovered from the dental plaque filtrate; host-range studies indicated that the bacteriophage had a narrow range of activity (within the samples tested). Conclusion: This study has indicated that it is possible to isolate bacteriophages specific to $S$. mutans from the oral cavity. Further work is required to prepare an effective mix of bacteriophages that are suitable for targeting cariogenic bacteria within a plaque biofilm and potentially, these bacteriophages could be incorporated into future caries-management programmes.

Keywords: Streptococcus mutans, bacteriophage, phage therapy, dental caries, dental plaque, caries prevention.

Copyright @ 2020: This is an open-access article distributed under the terms of the Creative Commons Attribution license which permits unrestricted use, distribution, and reproduction in any medium for non-commercial use (NonCommercial, or CC-BY-NC) provided the original author and source are credited.

\section{INTRODUCTION}

Dental caries remain a highly prevalent disease in the human population in spite of its easily preventable nature. The aetiology of dental caries is multifactorial and all factors involved in its development have been studied extensively, including the role of various microorganisms.

The oral microbiome consists of a diverse range of bacteria, viruses and fungi. Ecological imbalances favouring the growth of cariogenic bacteria and causing metabolic disharmony can lead to the development of dental decay [1], with Streptococcus mutans ( $S$. mutans) implicated as a primary odontopathogen and important marker of caries [2, 3]. Hence, $S$. mutans is a prime target in caries prevention and management. S. mutans are gram-positive, nonmotile cocci. They show extraordinary ability to survive and flourish in a low $\mathrm{pH}$ environment and have an extensive range of genes for carbohydrate uptake and metabolism [4]. S. mutans' virulence factors include production of extracellular polysaccharides, glucosedependent and glucose independent adhesion and contribution towards biofilm formation. Biofilms shows increased resistance to external and internal stresses and existence in biofilms can further influence growth rate, quorum sensing and gene expression of S. mutans [5]. S. mutans are also capable of producing bacteriocins known as mutacins against other bacteria [5, 6]. All these factors aid in the growth, survival and persistence of S. mutans [7].

Traditional caries preventive strategies such as oral hygiene measures and diet modification indiscriminately target commensals such as Streptococcus spp., Actinomyces and Veillonella along with odontopathogens such as $S$. mutans and can create 
open, non-competitive surfaces for pathogens to recolonize the oral cavity [8]. Various approaches eliminating or diminishing the cariogenic potential of $S$. mutans have been tested experimentally and reported in literature. Some of the most notable ones are the use of probiotics [9], bacterial replacement therapy [10], antimicrobial peptides [11], immunisation [12], interference with quorum sensing [7] and bacteriophage therapy [13].

Bacteriophages are self-replicating viruses that specifically infect bacteria and are usually isolated from the same environment as their host. Depending on the type, bacteriophages may reproduce by lytic or lysogenic cycles or both [14]. Bacteriophages are highly specific and infect single or very few bacterial strains. They tend to be more numerous than bacteria and can also mutate more rapidly. Bacteriophage therapy is a treatment approach that utilises bacteriophages to combat infections by aiming to lower the bacterial load. Lytic phages are most commonly exploited as they destroy the bacterial host when they reproduce as opposed to lysogenic phages which do not kill the cells they infect. Bacteriophages may be delivered topically or orally. Thus far, phage therapy has not been associated with any major side effects. They are inherently non-toxic, demonstrate lack of crossresistance with antibiotics and due to their limited host range, reduce the potential for development of resistance [15]. Production of phages is becoming increasingly economical with technological advancements and may be equivalently priced if not cheaper than development of new antibiotics [15, 13].

Bacteriophages have successfully been used for the treatment of various local and systemic infections in humans such as the management of antibiotic-resistant septicaemia [16, 17]. Studies have also been undertaken to assess the potential of bacteriophages in the management of dental infections such as periodontitis. In vitro studies have evaluated the effect of bacteriophages on endodontic [18] and periodontal $[19,20]$ pathogens and 47 some of these studies have shown promising results. However, studies investigating the role of bacteriophage therapy on cariogenic activity are fewer in number. The use of this approach in management of caries warrants interest as phages are target specific and unlikely to affect other oral flora. To date, three $S$. mutans phages have been isolated from saliva and their genomes sequenced [21, $22,1]$. Other similar studies $[23,24]$ failed to yield any $S$. mutans- specific phages. This study aims to isolate $S$. mutans and detect its specific phage from dental plaque.

\section{MATERIALS AND METHODS}

Human subject enrolment: Ethical approval was obtained from The East of Scotland Ethics Service, IRAS ref. nos. 195501 REC Ref: 16/ES/0124 and information leaflets were sent out to patients selected on the basis of convenience sampling. Written consent was obtained from patients at the Edinburgh Dental Institute, Scotland on the day of sample collection. Participants were above 18 years of age, free of any serious systemic illness and showed clinical or radiographic signs of dental decay. Individuals undertaking a course of antibiotics were excluded. A total of thirty-nine samples were collected between February and March 2017.

Sample collection and processing: Plaque samples were collected using ESwabTM Liquid Amies Collection and Transport System (catalogue no. 481CE; Copan Italia, Italy) and processed on the day of collection (within 3 hours). Each swab consisted of a sterile, flocked nylon fibre swab tip in $1 \mathrm{ml}$ of liquid Amies transport medium. The samples were centrifuged at $8000 \mathrm{xg}$ for 3 min using the Fisherbrand ${ }^{\mathrm{TM}}$ Mini Vortex Mixer (Fisher Scientific, Leicestershire, UK) to allow complete elution of the dental plaque into the liquid. $0.1 \mathrm{ml}$ was used for bacterial isolation (as below) and the remainder of the sample was filtered through $0.45 \mu \mathrm{m}$ filter (Gilson ${ }^{\circledR}$ ) and filtrates from each day of sampling were pooled together and stored at $4^{\mathrm{O}} \mathrm{C}$.

Bacterial isolation: Direct streaking and spread plating techniques were utilised. Plaque samples were serially diluted in distilled water (undiluted, $10^{-1}$, $10^{-2}, 10^{-3}, 10^{-4}, 10^{-5}$, and $10^{-6}$ ) and plated onto selective medium, Tryptone-Yeast extract-Cysteine-SucroseBacitracin agar (TYCSB) in order to isolate S. mutans. The culture medium was prepared using $0.2 \mathrm{~g}$ L- cystine $\mathrm{HCl}$ monohydrate (Sigma Ultra), $15 \mathrm{~g}$ bacteriological peptone (Oxoid), 5g yeast extract (Oxoid), 0.1g Sodium sulphite (Sigma), 0.1g Sodium chloride (Fisher), 1.0g Sodium phosphate (Sigma), 2.0g Sodium hydrogen carbonate (Fisher), 20g Sodium acetate (GPR) 20\% w/v sucrose (Sigma), 15g granulated agar (Oxoid), $0.1 \mathrm{U} / \mathrm{ml}$ bacitracin (Sigma), distilled water. TYCSB culture medium was selected as it demonstrates high selectivity for mutans Streptococcci as compared to non-mutans bacteria. Additionally, highest rates of $S$. mutans recovery are associated with it as compared to other media [25].

Brain Heart Infusion (BHI) agar, prepared from Brain Heart Infusion dehydrated powder, is a rich non-selective culture medium and samples were cultured on it in addition to TYCSB to boost the growth of any $S$. mutans present. Comparison of bacterial growth on both media ensured complete recovery of $S$. mutans from all samples. Plates were incubated at $37^{\circ} \mathrm{C}$ for 48 hours. Typed strain of S. mutans (20523 Streptococcus mutans) was used as standard for morphological comparison. Suspect colonies were subcultured until a pure form was obtained by repeated replating. The colonies were subjected to biochemical tests including catalase test and Gram staining. Catalase test was performed by adding a small amount of bacterial culture onto a glass slide with a few drops of hydrogen peroxide. Production of bubbles indicated a 
positive result. Colonies responding negatively to catalase test were subjected to Gram staining. Finally, molecular testing was carried out to confirm the identity as $S$. mutans using colony PCR with primers specific for amplification of the $g t f B$ gene.

Isolation of bacteriophage: Spot assays were carried out to determine the presence of bacteriophages. Bacterial lawn growth was obtained by adding $50 \mu \mathrm{L}$ $1 \mathrm{M}$ Magnesium Chloride $\left(\mathrm{MgCl}_{2}\right), 50 \mu \mathrm{L} 1 \mathrm{M}$ Calcium Chloride $\left(\mathrm{CaCl}_{2}\right)$ to $3 \mathrm{~mL}$ of soft $\mathrm{BHI}$ overlay agar ( $0.7 \%$ agar) along with $200 \mu \mathrm{L}$ of overnight cultures of $S$. mutans strains from Table 1 . The mixture was poured over BHI agar plate and allowed to set. Pooled filtrates i.e. phage lysates, derived from dental plaque samples (Table 2) were used in spot assays. $10 \mu \mathrm{L}$ of the phage lysate was spotted on the plates and these were incubated for 24 hours at $37^{\circ} \mathrm{C}$. Negative controls were set up for each spot assay.

Series of enrichments of the filtrates with a combination of bacteria was carried out to boost any phages present. The enriched filtrates were also used in spot assays against the same bacterial hosts. Clear zones of lysis on the bacterial lawn were indicative of phage presence.

Phage quantification: Plaque assays were carried out using the filtrate and host showing positive results in the spot assays. This was done to confirm the presence of phage as noted by spot assays and to quantify the level of phage available in the filtrate. 1:10 serial dilutions were made for the enriched dental plaque filtrate. $100 \mu \mathrm{L}$ of the filtrate at each dilution was added to BHI broth along with $50 \mu \mathrm{L} 1 \mathrm{M} \mathrm{MgCl} 2,50 \mu \mathrm{L}$ $1 \mathrm{M} \mathrm{CaCl} 2$ and $0.5 \mathrm{~mL}$ glycine. The mixture was poured over BHI agar plate and then incubated for 24 hours at $37^{\mathrm{O}} \mathrm{C}$. A negative control without any filtrate was also set up.

\section{RESULTS}

\section{S. mutans isolation and strain collection}

Thirty-nine dental plaque samples were collected in total. Two samples were excluded due to duplication of subjects. All samples were used for bacteriophage filtrate assays (see below) and microbiological assessment was carried out on 13 samples, with the aim of isolating S. mutans. Wan et al. [25] have described the colony morphology of $S$. mutans on TYCSB agar as tiny white colonies within a clear zone. Typed strain of $S$. mutans grown on TYCSB selective media was used as a positive control. Wildtype colonies that showed a similargrainy/ crystalline'appearance to the typed strain (Figure $1 \mathrm{~A}$ ) were considered to be putative $S$. mutans and were subjected to biochemical analysis. If more than one colony morphology was observed from a sample culture, both colony types were tested and treated as separate isolates. $S$. mutans are catalase negative bacteria and colonies testing negative in this test were Gram stained for further identification. S. mutans are described as Gram positive cocci organised in chains [26], thus Gram positive colonies (i.e. those stained violet when viewed microscopically; Figure 1B) were selected for molecular analysis to allow final identification. Thirty heterogeneous isolates were obtained from the culture of the plaque samples in total and these were all analysed as described above. Of these, seven isolates were positively identified as $S$. mutans following molecular analysis (Table 1).

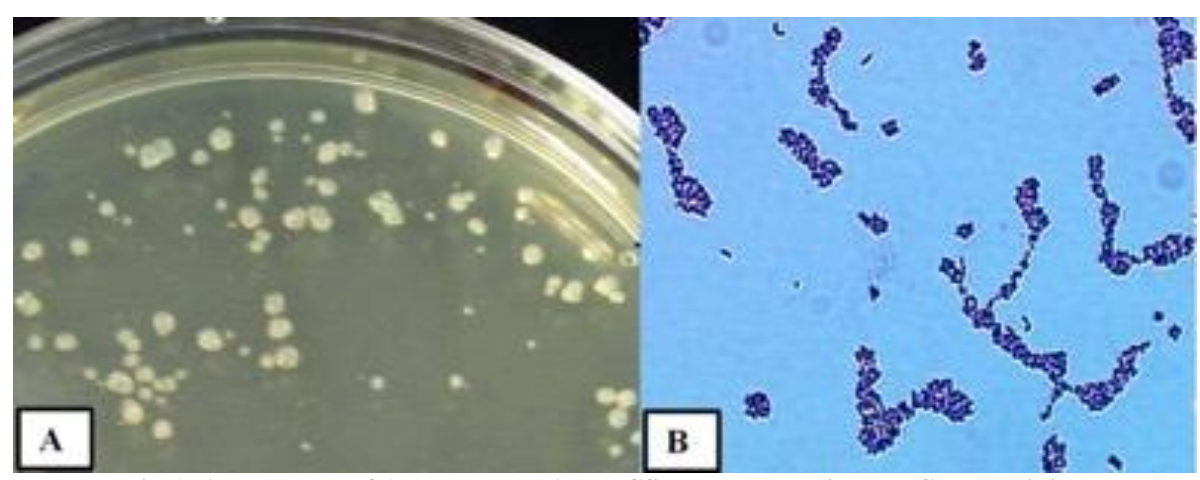

Fig-1: Appearance of S. mutans on: A: TYCSB culture medium B: Gram staining 
Nazish Munir Mohamedhussein \& J I Foley; Saudi J Oral Dent Res, Jan 2020; 5(1): 56-61

Table-1: 'Wild-type' $S$. mutans isolated from dental plaque

\begin{tabular}{|c|c|c|c|c|c|}
\hline $\begin{array}{c}\text { Sample } \\
\text { ID }\end{array}$ & $\begin{array}{c}\text { Colony morphology } \\
\text { SO1 }\end{array}$ & $\begin{array}{c}\text { Catalase } \\
\text { test }\end{array}$ & $\begin{array}{c}\text { Gram } \\
\text { Test }\end{array}$ & $\begin{array}{c}\text { PCR } \\
\text { identification }\end{array}$ & Isolate \\
\hline SO1 & $\begin{array}{c}\text { Very small, grainy colony, translucent- white } \\
\text { colour }\end{array}$ & - & + & + & SO113021701 \\
\hline SO2 & $\begin{array}{c}\text { Medium sized, granular translucent- white } \\
\text { colony }\end{array}$ & - & + & + & SO113021702 \\
\hline SO9 & $\begin{array}{c}\text { Small, crystalline, golden-brown colony with a } \\
\text { clear halo around it }\end{array}$ & - & + & + & SO903031701 \\
\hline SO9 & Small, white, crystal-like colony with a clear \\
halo around it & - & + & + & SO00903031702 \\
\hline S10 & large, white, crystal-like colony & - & + & + & S1003031701 \\
\hline S39 & very small translucent-white crystalline colony & - & + & + & S3909021701 \\
\hline
\end{tabular}

\section{Spot Assays and Phage isolation}

Spot assays were carried out to screen for the presence of phages. The negative control plates primarily showed good bacterial lawn growth. Pooled dental plaque filtrates and their enrichments were utilised (Table 2) against the bacteria isolated (listed in Table 1). All original filtrates yielded negative results in spot assays. Subsequently a series of enrichments were carried out for the filtrates and spot assays repeated.
Evidence of lysis was noted in spot assays against S. mutans SO213021701 for the second round of enrichment on Filtrate 1, as demonstrated by clearing of the bacterial lawn in the region of filtrate application with denser, centrally located, clear plaques (Figure 2). The same enriched filtrate showed no activity against the other wild-type $S$. mutans isolates and no bacteriophage activity was detected with any of the other filtrates or enrichments.

Table-2: Dental plaque filtrates used in phage isolation

\begin{tabular}{|c|c|c|}
\hline Sample ID & Filtrate ID & Number of enrichments carried out \\
\hline $1-3$ & 1 & 2 \\
\hline $4-7$ & 2 & 3 \\
\hline $8-12$ (excluding 11) & 3 & 2 \\
\hline $13-27$ & 4 & 1 \\
\hline $28-34$ & 5 & 1 \\
\hline $36-38$ & 6 & - \\
\hline 39 & 7 & 2 \\
\hline
\end{tabular}

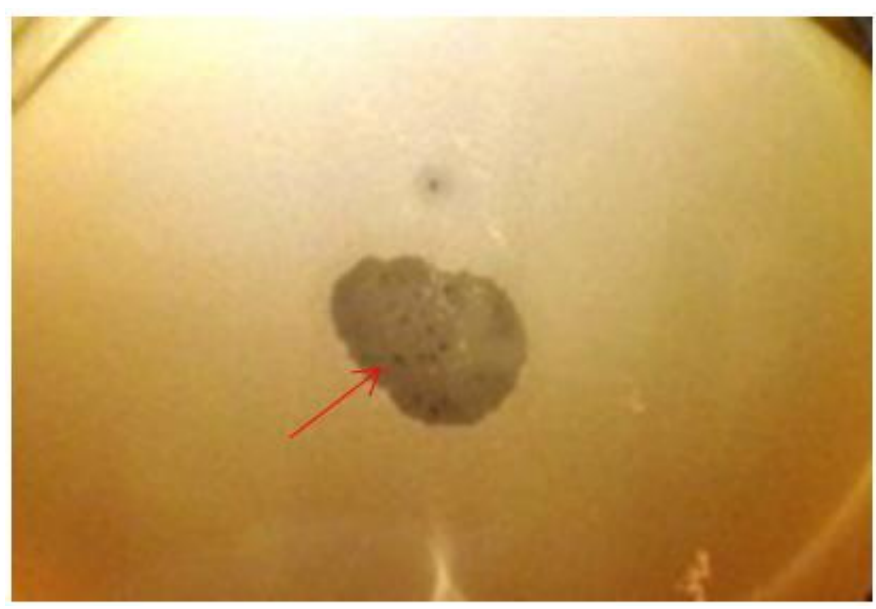

Fig-2: Spot assay (using $S$. mutans SO213021701 and $2^{\text {nd }}$ round of enrichment on Filtrate 1) indicating clearing of bacterial lawn at site of filtrate spotting with multiple, circular clear plaques centrally located (arrow)

\section{Plaque Assay}

Filtrate 1- enrichment 2 showing activity in the spot assay was diluted 1:10 and plaque assays carried out, demonstrating a clear titration effect of the distinct, round, homogenous plaques in the bacterial lawn (Figure 3), from which a titre of $1.27 \times 10^{7} \mathrm{PFU} / \mathrm{mL}$ was calculated (from the $10^{-4}$ dilution). 


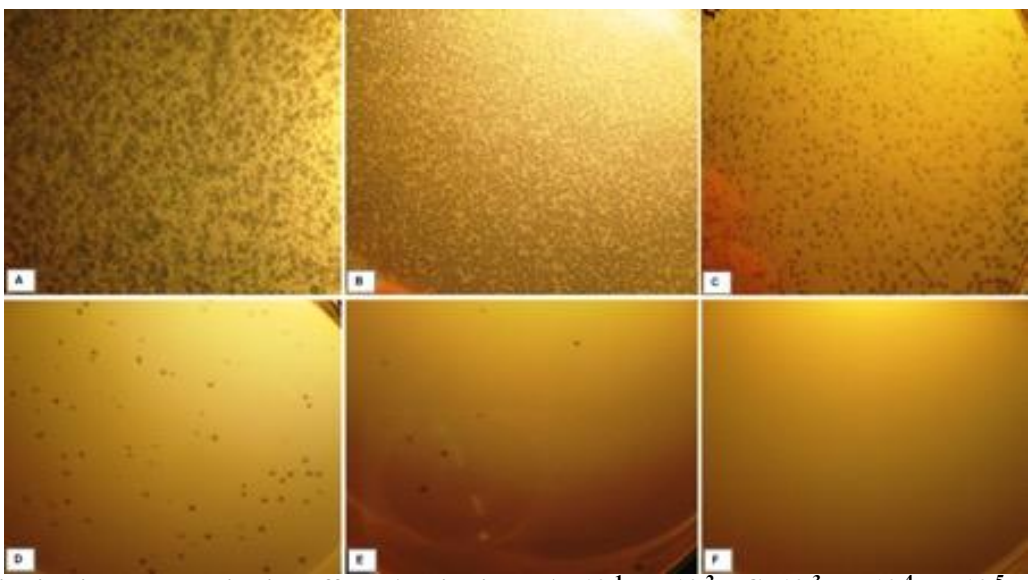

Fig-3: Plaque assays indicating a clear dilution effect. At dilutions: A: $10^{-1}, \mathrm{~B}: 10^{-2}$, C: $10^{-3}, \mathrm{D}: 10^{-4}, \mathrm{E}: 10^{-5}, \mathrm{~F}: 10^{-6}$ using $S$. mutans SO213021701 for the $2^{\text {nd }}$ round of enrichment on Filtrate 1

\section{DISCUSSION}

$S$. mutans is considered to be the principal pathogen in the development of dental caries and consequently remains the chief target in many novel caries preventive approaches.

Bacteriophage therapy has successfully been initiated in humans to manage various infections [27, 16]. Utilising this approach in management of caries has also garnered interest in recent times. The oral cavity has been a source of numerous bacteriophages active against various bacteria, however only three bacteriophages with activity against $S$. mutans have been reported in literature. These include M102 [21], M102AD [22] and \$APCM01 [1]; all of which presented with a closely related genome.

In contrast to previous studies, wild-type strains of $S$. mutans were isolated from dental plaque of individuals instead of using typed strains available from laboratories. Laboratory strains are cultured under optimal conditions and may lack various specific characteristics that are acquired by microorganisms in a complex ecological setting such as the oral cavity [28]. As a result the bacteria may behave differently and in order to avoid this discrepancy wild strains were obtained and purified. TYCSB culture medium was used due to its exemplary sensitivity and selectiveness for isolation of S. mutans. As previously mentioned TYCSB medium gives the highest recovery rates of $S$. mutans and inhibits growth of non-mutans Streptococci to a greater extent as compared to other selective culture media. It also allows identification of S. mutans based on a characteristic morphological appearance [25].

In opposition to previous studies on the subject, our strategy was isolation from dental plaque instead of saliva. Collection of plaque using a swab offers an easier, time efficient and perhaps more effective sample collection. There has been limited success in isolation of $S$. mutans specific bacteriophages from the oral cavity in the past. Our study was successful in identifying a phage from only thirty-nine samples. This can perhaps be attributed due to dental biofilm collection instead of saliva.

The bacteriophage isolated demonstrated an extremely limited host range but this reflects the inherent property of phages and is consistent with the observations reported in literature. This has traditionally been overcome by using a cocktail of phages to broaden the coverage of the target pathogen [29].The present study can be furthered by determining the genome sequence of the isolated bacteriophage to allow its complete identification and classification. The effect of the bacteriophage on $S$. mutans strains individually as well as a part of a biofilm model should also be assessed.

In a time when resistance to antibiotics is a growing concern, therapeutic use of bacteriophages offers a suitable alternative. With further research bacteriophage therapy could perhaps be integrated into the management of dental caries.

\section{ACKNOWLEDGEMENTS}

This study was run jointly by the University of Edinburgh, NHS Lothian and Edinburgh Napier University. Partial funding was obtained from NHS endowment fund and Edinburgh Napier University.

\section{REFERENCES}

1. Dalmasso, M., De Haas, E., Neve, H., Strain, R., Cousin, F. J., Stockdale, S. R., \& Hill, C. (2015). Isolation of a novel phage with activity against Streptococcus mutans biofilms. PLoS One, 10(9), e0138651.

2. Russell, R. R. B. (2008). How has genomics altered our view of caries microbiology?. Caries research, 42(5), 319-327.

3. Russell, R. R. (2009). Changing concepts in caries microbiology. American journal of dentistry, 22(5), 304. 
4. Bradshaw, D. J., \& Lynch, R. J. (2013). Diet and the microbial aetiology of dental caries: new paradigms. International dental journal, 63, 64-72.

5. Banas, J. A. (2004). Virulence properties of Streptococcus mutans. Front Biosci, 9(10), 126777.

6. Krzyściak, W., Jurczak, A., Kościelniak, D., Bystrowska, B., \& Skalniak, A. (2014). The virulence of Streptococcus mutans and the ability to form biofilms. European Journal of Clinical Microbiology \& Infectious Diseases, 33(4), 499515.

7. Senadheera, D., \& Cvitkovitch, D. G. (2008). Quorum sensing and biofilm formation by Streptococcus mutans. In Bacterial Signal Transduction: Networks and Drug Targets (pp. 178-188). Springer, New York, NY.

8. He, X. S., \& Shi, W. Y. (2009). Oral microbiology: past, present and future. International journal of oral science, $1(2), 47$.

9. Anusha, R. L., Umar, D., Basheer, B., \& Baroudi, K. (2015). The magic of magic bugs in oral cavity: Probiotics. Journal of advanced pharmaceutical technology \& research, 6(2), 43.

10. Pan, W., Mao, T., Xu, Q. A., Shao, J., Liu, C., \& Fan, M. (2013). A new gcrR-deficient Streptococcus mutans mutant for replacement therapy of dental caries. The Scientific World Journal, 2013.

11. Ren, Z., Cui, T., Zeng, J., Chen, L., Zhang, W., Xu, X., .. \& Li, Y. (2016). Molecule targeting glucosyltransferase inhibits Streptococcus mutans biofilm formation and virulence. Antimicrobial agents and chemotherapy, 60(1), 126-135.

12. Gambhir, R. S., Singh, S., Singh, G., Singh, R., Nanda, T., \& Kakar, H. (2012). Vaccine against dental caries-an urgent need. $J$ Vaccines Vaccin, 3(2), 136.

13. Bhardwaj, S. B. (2014). Bacteriophage Therapy: A possible new alternative for oral diseases. Int. J. Curr. Microbiol. App. Sci, 3(6), 437-442.

14. Goodridge, L. A. W. R. E. N. C. E., \& Abedon, S. T. (2003). Bacteriophage biocontrol and bioprocessing: application of phage therapy to industry. SIM news, 53(6), 254-262.

15. Loc-Carrillo, C., \& Abedon, S. T. (2011). Pros and cons of phage therapy. Bacteriophage, 1(2), 111114.

16. Weber-Dabrowska, B., Mulczyk, M., \& Górski, A. (2003). Bacteriophages as an efficient therapy for antibiotic-resistant septicemia in man. In Transplantation proceedings (Vol. 4, No. 35, pp. 1385-1386).

17. Weber-Dąbrowska, B., Jończyk-Matysiak, E., Żaczek, M., Łobocka, M., Łusiak-Szelachowska,
M., \& Górski, A. (2016). Bacteriophage procurement for therapeutic purposes. Frontiers in microbiology, 7, 1177.

18. Paisano, A. F., Spira, B., Cai, S., \& Bombana, A. C. (2004). In vitro antimicrobial effect of bacteriophages on human dentin infected with Enterococcus faecalis ATCC 29212. Oral microbiology and immunology, 19(5), 327-330.

19. Machuca, P., Daille, L., Vinés, E., Berrocal, L., \& Bittner, M. (2010). Isolation of a novel bacteriophage specific for the periodontal pathogen Fusobacterium nucleatum. Appl. Environ. Microbiol., 76(21), 7243-7250.

20. Phee, A., Bondy-Denomy, J., Kishen, A., Basrani, B., Azarpazhooh, A., \& Maxwell, K. (2013). Efficacy of bacteriophage treatment on Pseudomonas aeruginosa biofilms. Journal of endodontics, 39(3), 364-369.

21. Van der Ploeg, J. R. (2009). Analysis of CRISPR in Streptococcus mutans suggests frequent occurrence of acquired immunity against infection by M102like bacteriophages. Microbiology, 155(6), 19661976.

22. Delisle, A. L., Guo, M., Chalmers, N. I., Barcak, G. J., Rousseau, G. M., \& Moineau, S. (2012). Biology and genome sequence of Streptococcus mutans phage M102AD. Appl. Environ. Microbiol., 78(7), 2264-2271.

23. Hitch, G., Pratten, J., \& Taylor, P. W. (2004). Isolation of bacteriophages from the oral cavity. Letters in applied microbiology, 39(2), 215219.

24. Bachrach, G., Leizerovici-Zigmond, M., Zlotkin, A., Naor, R., \& Steinberg, D. (2003). Bacteriophage isolation from human saliva. Letters in Applied Microbiology, 36(1), 50-53.

25. Wan, A. K. L., Seow, W. K., Walsh, L. J., \& Bird, P. S. (2002). Comparison of five selective media for the growth and enumeration of Streptococcus mutans. Australian dental journal, 47(1), 21-26.

26. Facklam, R. (2002). What happened to the streptococci: overview of taxonomic and nomenclature changes. Clinical microbiology reviews, 15(4), 613-630.

27. Weber-Dabrowska, B., Mulczyk, M., \& Górski, A. (2001). Bacteriophage therapy for infections in cancer patients. Clinical and Applied Immunology Reviews, 1(3-4), 131-134.

28. Palková, Z. (2004). Multicellular microorganisms: laboratory versus nature. EMBO reports, 5(5), 470476.

29. Lu, T. K., \& Koeris, M. S. (2011). The next generation of bacteriophage therapy. Current opinion in microbiology, 14(5), 524-531. 